\title{
Slurry shield tunneling in soft ground. Comparison between field data and 3D numerical simulation
}

https://doi.org/10.2478/sgem-2019-0003

received December 28, 2018; accepted May 7, 2019.

\begin{abstract}
In urban areas, the control of ground surface settlement is an important issue during shield tunnelboring machine(TBM)tunneling. These ground movements are affected by many machine control parameters. In this article, a finite difference (FD) model is developed using Itasca FLAC-3D to numerically simulate the whole process of shield TBM tunneling. The model simulates important components of the mechanized excavation process including slurry pressure on the excavation face, shield conicity, installation of segmental lining, grout injection in the annular void, and grout consolidation. The analysis results from the proposed method are compared and discussed in terms of ground movements (both vertical and horizontal) with field measurements data. The results reveal that the proposed 3D simulation is sufficient and can reasonably reproduce all the operations achieved by the TBM. In fact, the results show that the TBM parameters can be controlled to have acceptable levels of surface settlement. In particular, it seems that moderate face pressure can reduce ground movement significantly and, most importantly, can prevent the occurrence of face-expected instability when the shield crosses very weak soil layers. The shield conicity has also an important effect on ground surface settlement, which can be partly compensated by the grout pressure during tail grouting. Finally, the injection pressure at the rear of the shield significantly reduces the vertical displacements at the crown of the tunnel and, therefore, reduces the settlement at the ground surface.
\end{abstract}

Keywords: Shield tunneling; soil-structure interaction; 3D numerical simulation; back analysis; settlement.

\footnotetext{
*Corresponding author: Mohammed Beghoul, Laboratory of Research in Applied Hydraulics (LRHYA), Department of Civil Engineering, University of Batna 2-Mostepha Benboulaid, Algeria, E-mail: m.beghoul@univ-batna2.dz

Rafik Demagh: Laboratory of Research in Applied Hydraulics (LRHYA), Department of Civil Engineering, University of Batna 2-Mostepha Benboulaid, Algeria
}

\section{Introduction}

During the past decade, pressurized-face tunnel-boring machines (TBMs), such as slurry shield, have established itself as a proven technology. It is characterized by safety, excavation speed, and minimal impacts on the surrounding environment (Xie et al., 2016). It is usually used in urban areas where the control of ground movements is an essential task in the design of shallow tunnels. However, shield tunneling inevitably causes some ground movements that can have adverse effects on both buried and aboveground infrastructures and buildings (Zhang et al., 2017). Therefore, it is a major concern in underground works to estimate tunnelinginduced ground movements to avoid excessive settlement by taking appropriate countermeasures (Wang et al., 2013). These ground movements are strongly influenced by many machine control parameters: front support, taper of the TBM shield, injection procedure, and solidification of the grout. This complexity, along with the complexity of soil behavior, has encouraged the widespread use of numerical modeling analyses. At the beginning, the simulations of tunneling using TBMs were analyzed in 2D models. Panet (1988) and Benmebarek et al. (1998) used concepts of stress release and volume loss, respectively, at each stage of the underground work. However, these approaches require the use of empirical coefficients such as the deconfinement ratio to take into account the threedimensional effect. To assess the impact of the shield tunneling key components on ground movements, only a three-dimensional approach that takes into account each of them can directly reproduce the physics of the problem. In the recent years, 3D models become more and more used to accurately simulate the complexity of the tunneling process (Demagh et al. 2013; Chakeri et al. 2013; Lueprasert et al. 2017). Although some practical experience has been accumulated from many industry projects (Li et al., 2015), the phenomena induced by the passage of a TBM are still insufficiently known.

This article presents a complete 3D numerical simulation of a tunnel-boring process. This one is applied 


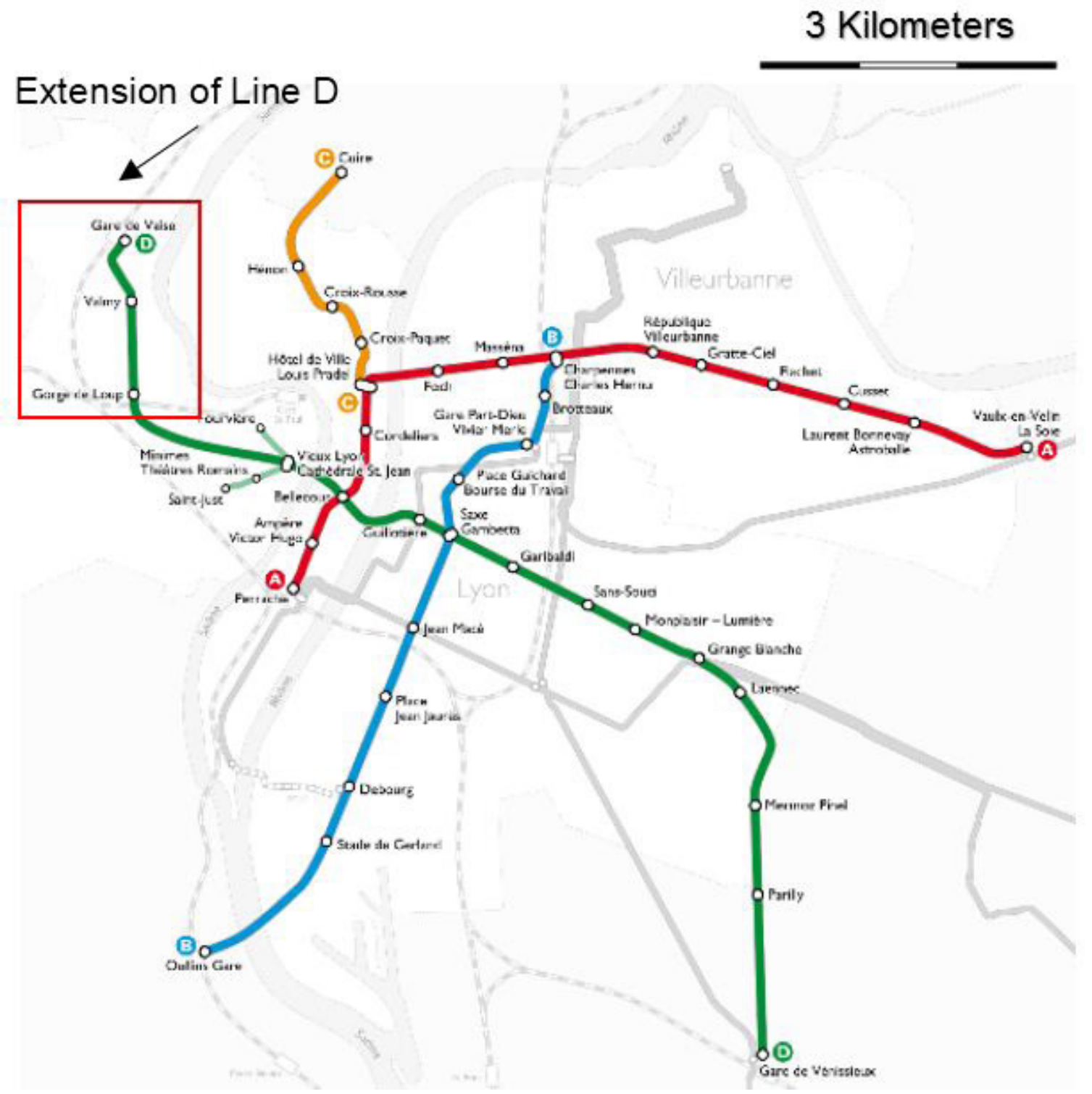

Figure 1: Lyon metro network.

to Lyon's subway for which sufficient experimental data are available (Ollier, 1997).

\section{Project overview and TBM}

\subsection{Site description}

The project is part of the extension of Lyon metro network, through an extension of line D between Gorge de Loup district and Vaise station (Figure 1). The line, entirely under the phreatic surface, is located at shallow depth in a densely urbanized area across very soft soils.
Geology condition is characterized by four types of ground that are successively encountered: Fills with 3-5 $\mathrm{m}$ in average thickness, silty alluvium in thin layers of sandy or clayey nature, sandy-gravel alluvium of rather coarse granulometry with particles of greater than 50 $\mathrm{mm}$ in diameters, and some blocks greater than $500 \mathrm{~mm}$ in diameter. Finally, there is a gneissic basement that goes from $80 \mathrm{~m}$ in depth at Vaise station to less than 20 $\mathrm{m}$ at Gorge de Loup (Figure 2). The silts, which are most often located at the upper part of the tunnel section, have natural water contents near the liquid limit and a low consistency index, which makes them very sensitive to disturbance. 


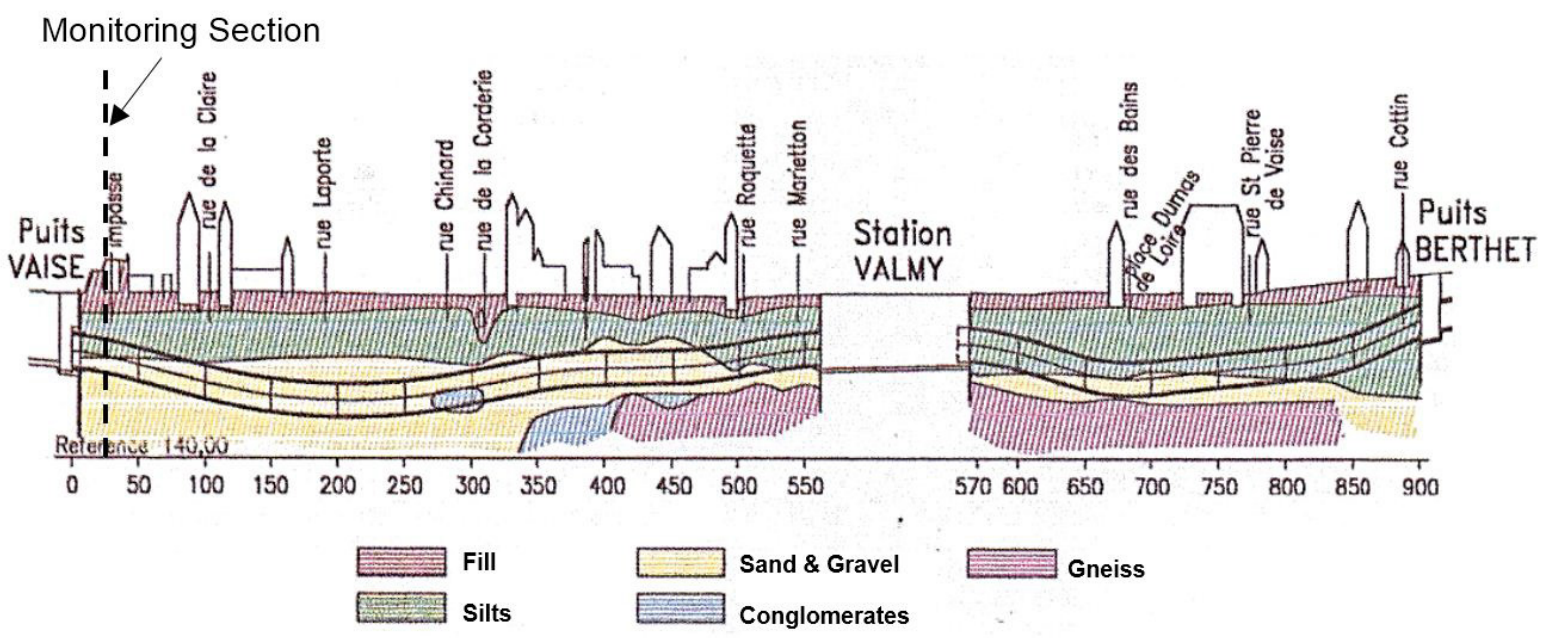

Figure 2: Geological profile.

\subsection{Monitoring section}

In order to build a database to qualify numerical simulation procedures, an experimental device was implemented. It is located in two different geological sites and consists of continuously measuring the displacements both on the surface and inside the massif, in order to identify the origin of the movements as well as to follow their evolution. The first site, which was intended to test the operating parameters of the TBM in a break-in area, consists of two sections (S1 and S2) with similar geologies but different geometries. They are located, respectively, at 30 and $65 \mathrm{~m}$ from the launching shaft, before crossing under the first buildings. The presence of a $6-\mathrm{m}$ high retaining wall makes the geometry of these two sections asymmetrical. These two sections are of great scientific interest because of their dissymmetry (because of the presence of a retaining wall) but also of their geological heterogeneity (they consist of an alternation of sands and clays). The first section (S1) is chosen to simulate in this study as shown in Figure 3. The second site is located $800 \mathrm{~m}$ from the "Vaise" station in a simple geometry zone.

In order to measure the displacements both at the surface and inside the massif, an instrumentation of the first tube (T1) of the first section (S1) has been carried out:

- Vertical displacements are measured within the massif using multipoint extensometers. An extensometer (EX 11) is installed directly above the tunnel;

- Surface settlement is provided by a system of leveling and completed by more specific topographic measurements;

- Horizontal displacements are measured using inclinometers (I14 and I17).

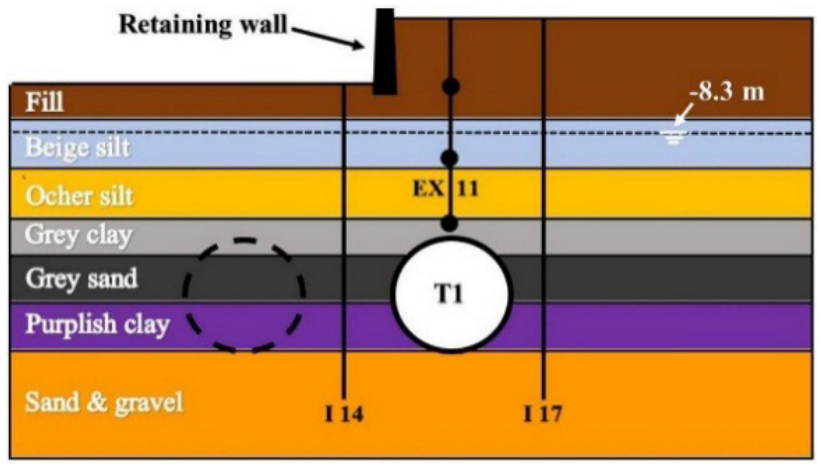

Figure 3: Geological profile.

\subsection{Slurry shield TBM}

Because of the risk of settlements, the slurry shield TBM was used in this project. The TBM consists of a shield (slightly conical) of about $7 \mathrm{~m}$ in length and $6.27 \mathrm{~m}$ in diameter and a 50-m long back-up train, and the TBM weighs nearly 300 tons. The machine is equipped with about 50 sensors recording the parameters of continuous operation. The tunnel is covered with prefabricated concrete segments (35 cm thick) placed under the shelter of the shield tail: when the TBM moves forward and the ring escapes from the shield tail, there remains an annular void of $13.5 \mathrm{~cm}$ (thickness of the shield tail) between the soil and the lining. In order to minimize the settlement, this void is immediately filled by an inert grout injected through six pipes situated on the shield periphery. Figure 4 and Table 1 summarize the principal geometrical notations of the tunnel, shield, and liner used in this study. 
Table 1: Tunnel parameters.

\begin{tabular}{llllllllllll}
\hline Section & $\begin{array}{l}\mathrm{H} \\
(\mathrm{m})\end{array}$ & $\begin{array}{l}\mathrm{L} \\
(\mathrm{m})\end{array}$ & $\begin{array}{l}\mathrm{C} / \mathrm{D} \\
-\end{array}$ & $\begin{array}{l}\mathrm{Hw} \\
(\mathrm{m})\end{array}$ & $\begin{array}{l}\text { Dext } \\
(\mathrm{m})\end{array}$ & $\begin{array}{l}\text { Dint } \\
(\mathrm{m})\end{array}$ & $\begin{array}{l}\mathrm{D} / 2 \\
(\mathrm{~mm})\end{array}$ & $\begin{array}{l}\text { Фext } \\
(\mathrm{m})\end{array}$ & $\begin{array}{l}\text { Фint } \\
(\mathrm{m})\end{array}$ & $\begin{array}{l}\text { Liner width } \\
(\mathrm{cm})\end{array}$ & $\begin{array}{l}\text { Liner thickness } \\
(\mathrm{cm})\end{array}$ \\
$\mathrm{P} 1-\mathrm{S} 1$ & 16.9 & 7.0 & 2.20 & 8.30 & 6.27 & 6.24 & 15 & 6.0 & 5.3 & 100 & 35 \\
\hline
\end{tabular}
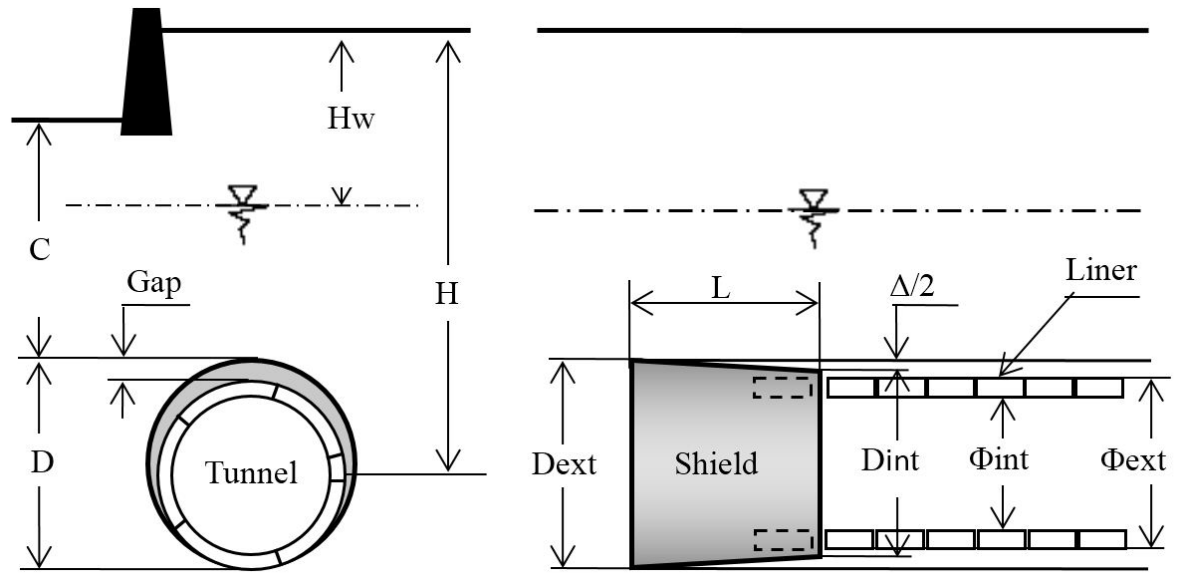

Figure 4: Tunnel, shield, and liner parameters.

\subsection{Field Measurements}

The site response at different excavation phases can be analyzed from the vertical movement recorded by extensometers located in the vertical axis during the digging of the first tube.

Figure 5 depicts the evolution of measured settlements in the longitudinal direction. Four source of ground movements related to the position of the tunnel boring machine are highlighted from these field data: movements because of the face approach and passage, movements along the shield, movements induced by the grout injection scheme, and, finally, movements related to the grout and the surrounding ground consolidation.

The ground begins to sink one diameter ahead to reach about $2 \mathrm{~mm}$ at the shield face passage. These low settlements, which are related to the reduction of the tangential stress at the tunnel periphery, indicate the excellent support by the pressurized bentonite slurry. In addition, the other hypothesis is that the shield extrados, perfectly lubricated by a possible movement of the injected liquid grout toward the cutterhead, allows the ground to slide more or less freely on the shield skin.

The ground movements keep increasing with the tunnel advance until reaching its maximum at the shield tail passage. These movements are due to the decreasing diameter of the shield over its length, creating a void between the shield and the soil that decompresses the

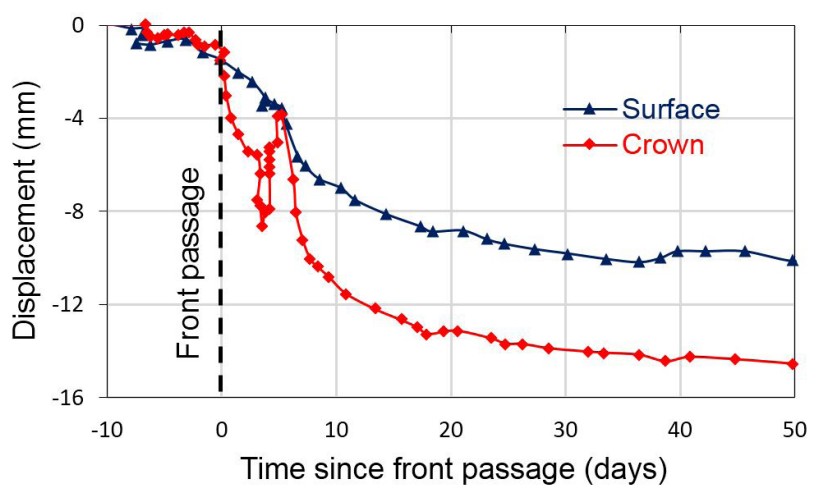

Figure 5: Evolution of settlements.

ground. After shield tail passage, the field results do not present any abrupt increase in surface settlement (despite the annular gap of $27 \mathrm{~cm}$ ), which shows the role of the injection pressure in filling this gap. The effect of the injection is marked by settlement and heave peaks. The maximum heave at the deepest point depends on the value and distribution of grouting pressures around the tunnel.

As the shield moves away the effect of the injection pressure decreases. The settlements are then increased until reaching nearly constant state. These movements can be attributed to the consolidation of the grout and the surrounding soil. 
Figure 6 shows the inclinometric lateral movements beside the tunnel, with respect to the tunnel face advancement. First, the soil mass between the tunnel crown and the invert moves outwards. The passage of the tunnel face induces an outward lateral movement of the ground at the tunnel axis level. This observed movement can be attributed to a reduction of the tangential stress at the excavation periphery. The lateral outward movement keeps increasing over the length of the shield until reaching a peak value at the grout injection phase. After the gradual disappearance of the injection pressure (about $20 \mathrm{~m}$ after the shield passage), the lateral movements are then stabilized after a slight convergence.

\section{Description of the proposed numerical model}

\subsection{General characteristics}

To assess the ground movements during slurry shield tunneling, a finite difference (FD) model is developed using Itasca Flac-3D. It includes the main components of slurry shield tunneling, such as slurry pressure on the excavation face, shield conicity, tail gap and tail grouting (including its solidification), and segmental lining. Regarding the model dimensions, general rules have been stated by various authors: Zhao et al. (2012) and Graziani et al. (2007). However, because shield tunneling causes relatively small plastic-deformation zones around the excavation, we can reduce the lateral extent of the model. Thus, the distance of 8D ahead and behind the monitoring section and that of $8 \mathrm{D}$ in lateral direction from the tunnel axis are sufficient to accurately simulate the tunneling process in this study. The dimension of model is $100 \mathrm{~m}(\approx 16 \mathrm{D})$ in the transverse direction, $100 \mathrm{~m}$ $(\approx 16 \mathrm{D})$ in the longitudinal direction, and $50 \mathrm{~m}(\approx 8 \mathrm{D})$ in vertical direction. The model element length equals the ring width of $1 \mathrm{~m}$ in the longitudinal direction within the tunnel excavation zone (y-direction). The displacement boundary is adopted in this study with zero transverse ( $\mathrm{x}$-axis) displacement at $\mathrm{x}=-100 \mathrm{~m}$ and $\mathrm{x}=100 \mathrm{~m}$ and zero longitudinal (y-axis) displacement at $\mathrm{y}=0$ and $\mathrm{y}=$ $100 \mathrm{~m}$. The top of the model boundary $(z=0)$ is set to be free, whereas the vertical movement at the bottom boundary $(z=-50 \mathrm{~m})$ is fixed.

These conditions are used throughout this study. It is common practice in tunneling to use symmetry with respect to a vertical plane including the tunnel axis and

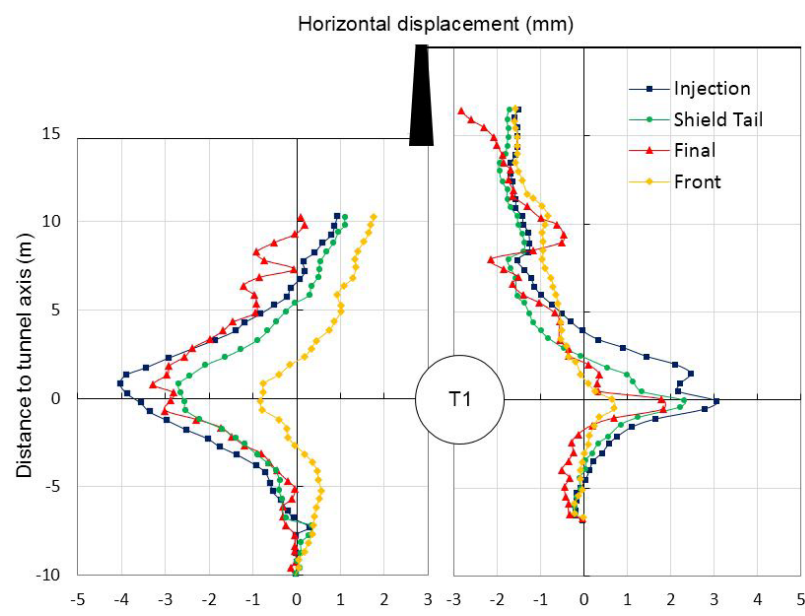

Figure 6: Lateral movements.

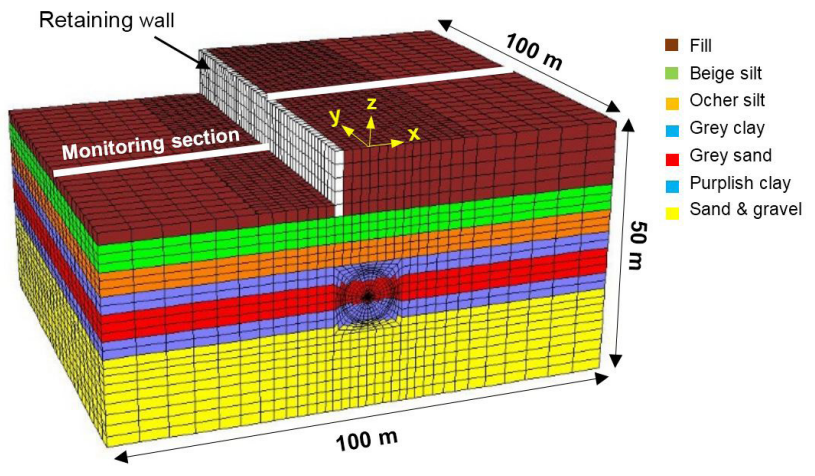

Figure 7: 3D numerical model.

thus model only half of the domain. In the present case, this symmetry is not used, because of the presence of a retaining wall at the surface. Figure 7 illustrates the general configuration of the numerical model.

\subsection{Interface constitutive model}

The interface model incorporated in FLAC-3D code (Falc ${ }^{3 D}$, 2000) and its components are used to simulate the soilshield contact. Figure 8 summarizes the main components of the interface constitutive model.

This interface is defined by the linear Coulomb shearstrength criterion, which limits shear force acting at the interface node, as well as normal and shear stiffness, tensile and shear bond strengths, and dilation angle, that causes an increase in effective normal force on the target face after the shear-strength limit is reached. The spring in the tangential direction, the slider, and its limit strength represent the Coulomb shear-strength criterion. 
Table 2: Mohr-Coulomb parameters.

\begin{tabular}{|c|c|c|c|c|c|c|c|}
\hline Layer & $\begin{array}{l}\text { Depth } \\
- \\
\mathrm{m}\end{array}$ & $\begin{array}{l}\text { Shear } \\
\text { (G) } \\
\mathrm{MPa}\end{array}$ & $\begin{array}{l}\text { Bulk } \\
\text { (K) } \\
\mathrm{MPa}\end{array}$ & $\begin{array}{l}\text { Weight } \\
\text { (g) } \\
\mathrm{kN} / \mathrm{m}^{3}\end{array}$ & $\begin{array}{l}\text { Cohesion } \\
\left(c^{\prime}\right) \\
\mathrm{KPa}\end{array}$ & $\begin{array}{l}\text { Friction } \\
\text { (j') } \\
0\end{array}$ & $\begin{array}{l}\text { Dilatancy } \\
\left(y^{\prime}\right) \\
0\end{array}$ \\
\hline Fill & $0-7$ & 2.92 & 7.8 & 18 & 30 & 30 & 17 \\
\hline Beige silt & $7-10$ & 2.74 & 7.3 & 19.5 & 12 & 33 & 20 \\
\hline Ocher silt & $10-13$ & 2.74 & 7.3 & 21 & 15 & 25 & 14 \\
\hline Grey clay & $13-15$ & 1.57 & 4.2 & 16.5 & 35 & 27 & 15 \\
\hline Grey sand & $15-17.5$ & 10.50 & 28 & 21 & 5 & 35 & 21 \\
\hline Purplish clay & $17.5-20$ & 5.16 & 13.8 & 18.5 & 35 & 27 & 15 \\
\hline Sand and gravel & $20-50$ & 10.50 & 28 & 21 & 0 & 34 & 20 \\
\hline
\end{tabular}

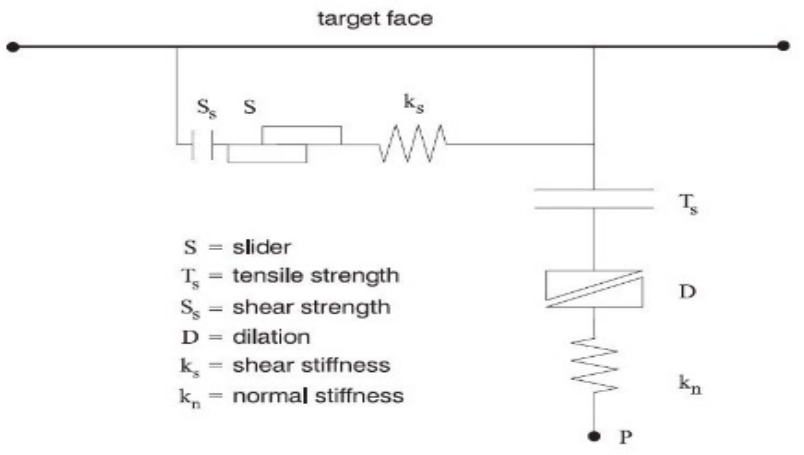

Figure 8: Components of the interface constitutive model.

The spring in the normal direction, the limit strength, and dilation represent the normal contact.

The material properties, particularly stiffness assigned to an interface, depend on the way in which the interface is used. In the case of soil-structure interaction, the interface is considered stiff compared to the surrounding soil. In fact, the stiffnesses Kn and Ks are difficult to estimate; several tests must be made in order to find the best compromise between, in the one hand, the tolerance of the interpenetration of the two faces in contact and, in the other hand, the penalties in terms of computation time. A good rule of thumb is that $\mathrm{Kn}$ and Ks be set to 10 times the equivalent stiffness of the stiffest neighboring zone.

In the contrary, for the resistance parameters, we take those of the least-resistant material, possibly reduced in case of smooth interface (case of soil-steel friction, for example).

It is important to note that interfaces are one sided in FLAC-3D; this differs from the formulation of two-sided interfaces in FLAC-2D.

\subsection{Initial conditions and material properties}

The initial distribution of vertical effective stress and horizontal effective stress are controlled by the given soil unit weight and the coefficient of earth pressure at rest, $K_{0}$ equal to 0.5 (normally consolidated soils). As the shield average advancement is $5 \mathrm{~m} /$ day (Ollier, 1997) and the permeability of the crossed soils is significant $\left(10^{-3}\right.$ to $\left.10^{-5} \mathrm{~m} / \mathrm{s}\right)$, the drained analysis is considered, taking into account the effective stresses. The ground is modeled using solid elements with 8-grid points. A linear elastic, perfectly plastic, Mohr-Coulomb constitutive model is used with no associative flow rule. This simple constitutive model is adopted because of the lack of data for some layers. The average soil parameters determined from geotechnical tests are summarized in Table 2. The shield, retaining wall, tunnel lining, and grouting layer are assumed to be elastic linear. The properties of the slurry shield are acquired from Katebi et al. (2015).

\subsection{Modeling slurry shield}

Real shields are either conical or telescopic (Maidl et al., 2012). In the proposed model, the shield is modeled as conical using thin solid elements with a length of 7 $\mathrm{m}$ with a tapering of $3 \mathrm{~cm}$ and includes $13.5-\mathrm{cm}$ annular gap (difference in radius between the extrados at the rear of the shield and the extrados of the segmental lining). The shield is considered perfectly rigid, the nodes are fixed according to the method called fixed center. This method is supposed to simulate the mechanical behavior of the shield (the shield, in the wait for the intake of the injected mortar, will somehow float by buoyancy and more or less stay in a central position especially during straight excavation phases). To reflect the realistic friction 


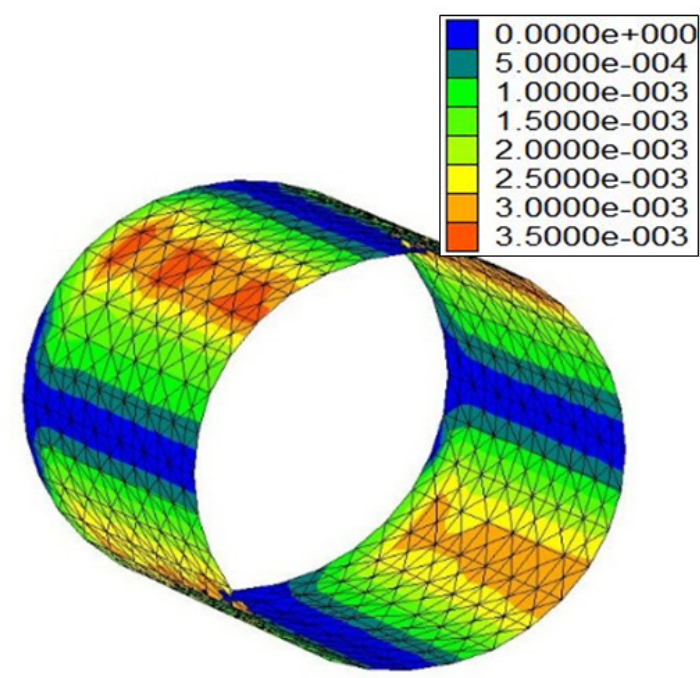

(a)

(b)

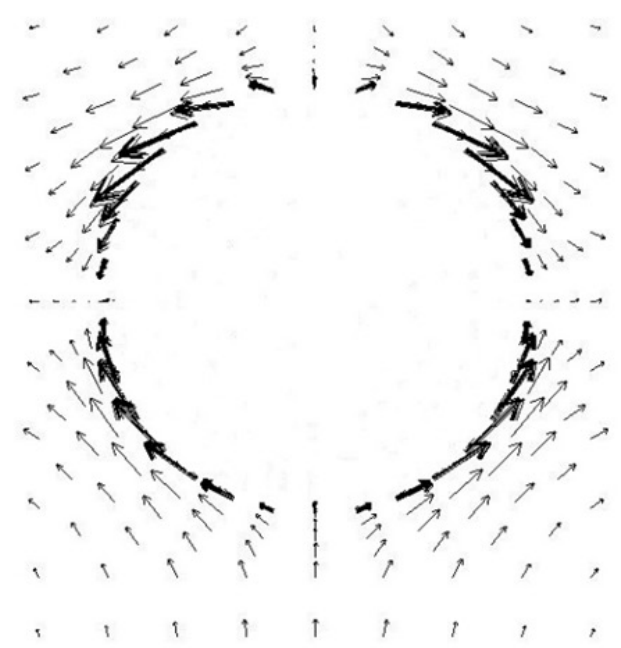

Figure 9: Performance of FLAC-3D interface element: (a) tangential displacement on the interface element (units: $m$ ) and (b) ground movements around the tunnel cavity.

distribution on the contact surface between the soil and the shield skin, an interface element was used. Laid on the shield extrados, the role of this interface is to block the radial ground convergence and also to allow the tangential convergence by arch effect. Figure 9 shows the interface element after being activated. The volume loss because of the shield conicity is partially compensated by the possible migration of the grout upward the shield. This migration is simulated by a correction of the shield conicity, set so as to reproduce a vertical displacement recorded on the construction site (back analysis on surface and/or tunnel crown vertical displacement) (Dias et al., 2000).

TBM face support was simulated by applying a pressure on the excavation face. The slurry pressure is assumed to linearly increase with depth and the gradient was modeled assuming a unit weight of $12 \mathrm{kN} / \mathrm{m}^{3}$. This face pressure plays an important role in ensuring tunnel face stability during the excavation process. Various approaches have been established to determine the tunnel proportional face pressure (Gugliemetti et al., 2008). The method generally adopted in shield tunneling is based on the total vertical stress $\sigma_{v}$ in the soil mass. The value of average face pressure at the tunnel axis is thus generally set equal to the horizontal ground pressure $\mathrm{K}_{0} \sigma_{\mathrm{v}}$ where $\mathrm{K}_{0}$ is the lateral earth pressure factor and $\sigma_{\mathrm{v}}$ is the vertical soil overburden pressure at the tunnel axis. The face pressure, in this construction site, is then set to about $160 \mathrm{KPa}$ (what corresponds to an air pressure equal to approximately 120 $\mathrm{KPa}$ if we reduce the pressure gradient of the slurry). In the proposed model, a moderate air pressure equal to 40
$\mathrm{KPa}$ was sufficient to ensure local face stability, which represents $30 \%$ of the air pressure instructed in this construction site.

\subsection{Modeling tail grouting}

In standard TBM operation, grout is injected at the rear of the shield to fill the annular gap (the gap between the extrados of the segmental lining and the surrounding ground). In the proposed model, tail grouting is simulated by filling the annular gap with "grout elements," which are 8 nodes, hexahedral solid elements. Elastic behavior was assumed for the injected grout elements. In practical engineering, the grouting material will change from the liquid state to the solid state. The elastic modulus of the grouting material will gradually increase with the construction process, to some extent, which reflects the change of the characteristics of the grouting material in the numerical model. In the proposed model, the liquid state of the grout is simulated with a ratio $K / G \approx 100$, where the solid state is simulated with a ratio $\mathrm{K} / \mathrm{G} \approx 1$ (Kasper and Meschke, 2006). Table 3 summarizes the values of the parameters adopted for the modeling of grout mechanical behavior. In this study, the grouting pressure distribution at the shield tail is assumed to linearly increase with depth and the gradient was modeled assuming a unit weight of $18 \mathrm{kN} / \mathrm{m}^{3}$ (Qiao et al., 2018). This has been simulated using distributional radial pressure. The common method to choose the value 
Table 3: The properties of grout in modeling.

\begin{tabular}{lllllll}
\hline Grout & $\begin{array}{l}\text { Unit weight } \\
\left(\mathrm{kN} / \mathrm{m}^{3}\right)\end{array}$ & $\begin{array}{l}\text { Young's modulus } \\
(\mathrm{MPa})\end{array}$ & $\begin{array}{l}\text { Poisson ratio } \\
(-)\end{array}$ & $\begin{array}{l}\text { Bulk modulus (K) } \\
(\mathrm{MPa})\end{array}$ & $\begin{array}{l}\text { Shear modulus (G) } \\
(\mathrm{MPa})\end{array}$ & $\begin{array}{l}\mathrm{K} / \mathrm{G} \\
(-)\end{array}$ \\
\hline Fluid state & 18 & 5 & 0.495 & 166.7 & 1.7 & 99.7 \\
Solid state & 18 & 30 & 0.20 & 16.7 & 12.5 & 1.3 \\
\hline
\end{tabular}

of the grout pressure makes use of the total vertical stress $\sigma_{\mathrm{v}}$ at the tunnel crown before excavation. The grout pressure $\sigma_{\text {inj }}$ is thus often set to $1.2 \sigma_{\mathrm{v}}$ (Do et al., 2014), which corresponds to about $310 \mathrm{KPa}$ in this construction site. However, the average site pressure really used in this site is equal to $300 \mathrm{KPa}$ at the upper injection pipes (Kastner et al., 1996), which is equivalent to $1.15 \sigma_{\mathrm{v}}$ at the tunnel crown. In our study, to reproduce the vertical displacements recorded on the site, we applied a grout pressure equal to $250 \mathrm{KPa}$, which corresponds to $95 \%$ of the vertical stress $\sigma_{\mathrm{v}}$. This shows that the pressure really transmitted to the ground is lower than the average pressure measured on the injection pipes. This difference is probably due to the flow of the grout and its impregnation of the surrounding ground.

The grout injection in the annular void is controlled in volume and pressure. The grout is simulated by adopting a uniform pressure, corresponding to the position of the injection pipes, which are distributed over the entire perimeter of the shield tail. The grout elements are reactivated in an initial compression state equal to the pressure with which they were injected. The injection pressure is applied to both the cylindrical surface of the excavated soil and external surface of the tunnel lining. It is set on measurement of the vertical displacement the closest to the tunnel crown. The annular void between the outside surface of the shield and the excavated soil makes the migration of some grout toward the shield possible. This migration is simulated by a correction of the shield conicity (Dias and Kastner, 2013).

Obviously, the grout solidification behind the shield tail was simulated in a very simple way in the above simulation. However, it was here chosen because of its simplicity and because it has already been successfully used in Dias and Kastner (2013), Do et al. (2014), and Mollon et al. (2013).

\subsection{Modeling excavation sequence}

Mechanized tunneling includes repetitive excavation steps, each of which consists of several consecutive actions (substeps) that must be properly simulated in

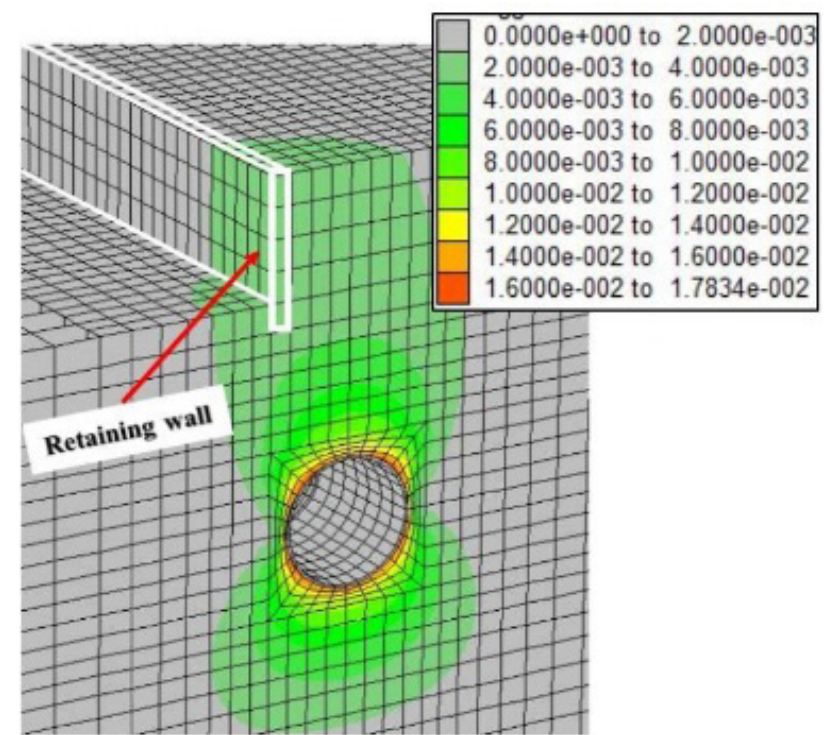

Figure 10: Contour of vertical displacements after complete installation of the shield (units: $\mathrm{m}$ ).

a numerical analysis. The excavation sequence can be described as follows:

Step 1: First, initial stress field has been assigned based on the stratigraphy and water ground level of model and the geostatic equilibrium achieved, with a lateral earth pressure factor $\mathrm{K}_{0}$ equal to 0.50 .

Step 2: After its generation (outside the massif), the shield is introduced step by step. Excavations are simulated by deactivation of the corresponding volume elements according to TBM advance ratio, equal to the length of the lining segment $(1 \mathrm{~m})$ and the diameter of the lining with the grout element. The interface element that is laid on the shield is activated since a contact is established with the surrounding ground. The face pressure is applied on the tunnel face. This excavation process is repeated until the total installation of the shield (after 7 excavation steps). Figure 10 shows the ground response after complete installation of the shield.

Step 3: In this step (after complete installation of the shield), the lining is installed at the rear of the shield. The grout elements are then activated in their liquid state with the application of the injection pressure on the boundary of the excavated tunnel and lining external face. After 

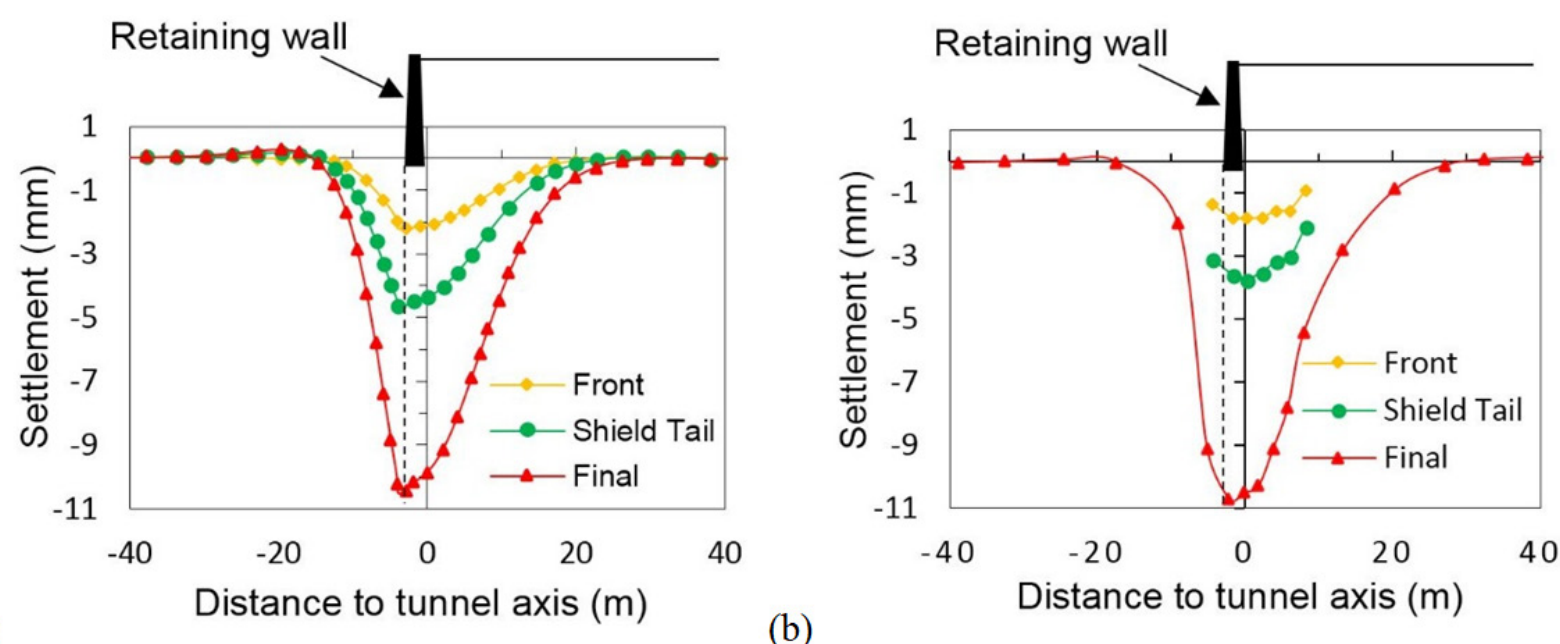

(a)

(b)

Figure 11: Transverse settlement troughs at different phases: (a) simulations and (b) field data.

installing five tunnel rings with lining elements at the back of the shield (the average advance of TBM in this project is $5 \mathrm{~m}$ a day), the injection pressure is deactivated gradually and the mechanical characteristics of the grout changed to the hardened ones. This procedure is repeated throughout the shield progression, until reaching the monitoring section (Figure 7) after a few tens of excavation steps.

The numerical model must satisfy two independent conditions: the first one corresponds to the retained ratio of the maximum unbalanced force. The ratio recommended by the authors of FLAC-3D, $10^{-5}$ in this case, is widely verified. The second condition is the number of excavations to reach the stationary section, this last condition is necessary to eliminate the border effects imposed by the truncation of the numerical model. In fact, monitoring section corresponds to the section of measurements on which the confrontations will be carried out.

\section{Comparison of simulation results and field measurements}

The simulation results are respectively confronted with field data collected on the construction tunnel site. These data include the movements of ground at the surface and inside the massif (both vertical and horizontal). The confrontation is carried out after the process of tunneling is completed.

\subsection{Transverse settlement troughs}

Figure 11 shows surface settlement profiles at different phases compared between FD analysis and field data. It can be noticed that the surface settlement troughs obtained from the 3D simulations are very close to the measured ones. In particular, their shape and the maximum settlements are in good agreement with field data at different working phases (front passage, shield tail passage, and final movements). Moreover, it is shown on the measured results (Figure 11b) that the more the settlement is important, the more the resulted surface trough is wide and vice versa. This is well reproduced by the 3D simulations (Figure 11a). The effect of the retaining wall makes the geometry and the final trough asymmetrical. However, this effect was a little bit overestimated by the 3D simulations.

Figure 12 superposes final surface settlement troughs. The curves are in good agreement, and all of their parts coincide. This confirms the accuracy of the proposed procedure.

Figure 13 shows transverse settlement trough profile at the ground surface and at the tunnel crown $(13 \mathrm{~m}$ from the surface) after complete passage of the shield from the monitoring section (about 10D behind tunnel face). It can be noticed that the ground movements are attenuated from tunnel crown to the surface. It goes from about $20 \mathrm{~mm}$ at the crown to about $10 \mathrm{~mm}$ at the surface in the tunnel axis. Figure 13 also shows that the surface trough is wider than that of the crown. The damping of movements from the crown to the surface is accompanied with a widening of surface trough. Furthermore, as the figure shows, the right side of the surface trough is wider than that in the 


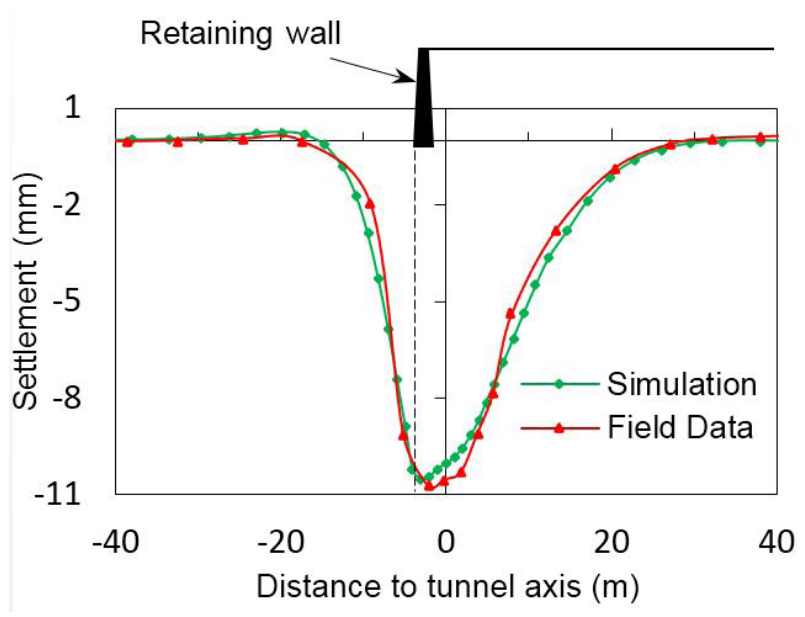

Figure 12: Final surface settlement troughs.

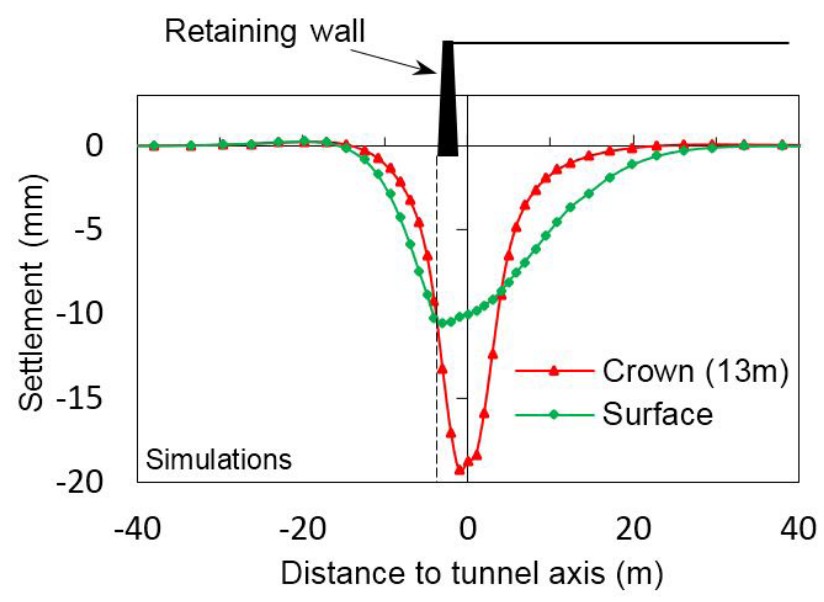

Figure 13: Transverse settlement troughs.

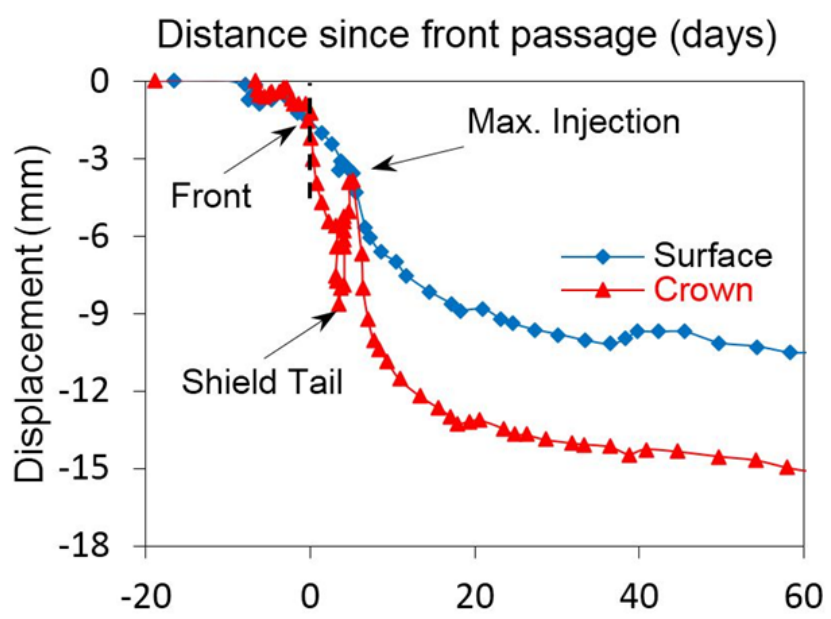

(a) left side. This is due to the difference in coverage between the two sides ( $13 \mathrm{~m}$ for right side and $7 \mathrm{~m}$ for left side). This confirms the aforementioned explanation on the transmission of movements. Finally, and in contrast to the movement transmission, the effect of the retaining wall is decreased with depth, as shown in Figure 13.

\subsection{Longitudinal settlement troughs}

To analyze the evolution of settlements in the longitudinal direction, tens of excavation steps were realized to illustrate a complete tunneling process. In the proposed model, because of the irregular progression of the TBM on the field (many stopping periods), it is difficult to find a correspondence in time to represent the shield progression in the y-direction. Therefore, to fix this issue, the shield progression is measured by "distance" instead (1 m at a time). Figure 14 shows the longitudinal settlement profile at the ground surface and at the tunnel crown.

The field response at various realization phases of the tunnel can be analyzed from the vertical movements recorded by the extensometer located in the vertical axis. Figure 14a shows the evolution of measured settlements using the extensometer located directly above the tunnel during the digging of the first tube. Analysis of these data permits highlighting several behavior phases related to the position of the TBM. The ground begins to sink slightly, at the surface as well as in depth, one diameter before the arrival of the shield and continues to subside until it reaches nearly $18 \%(2 \mathrm{~mm})$ of the maximum value $(11 \mathrm{~mm})$ during the front passage. Figure 14b shows that surface settlement is greater than crown settlement before

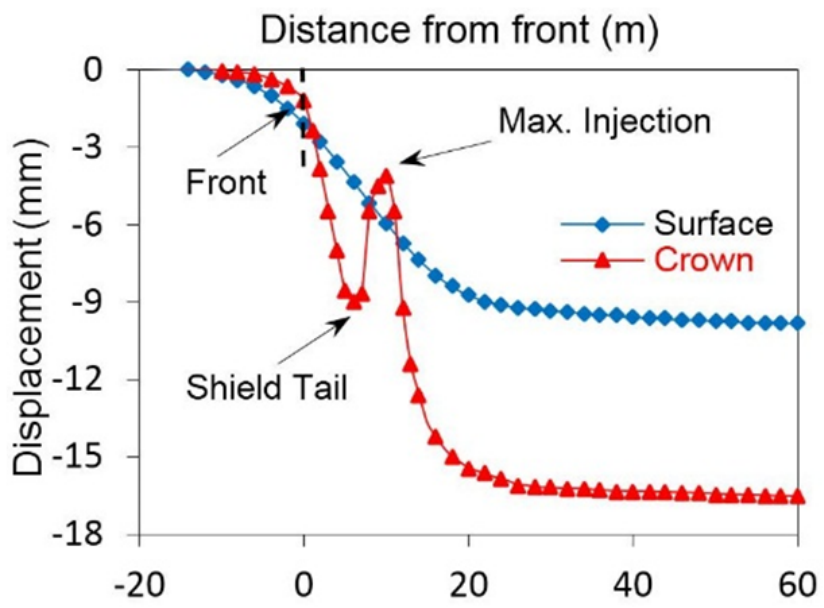

(b)

Figure 14 Longitudinal ground settlements: (a) field data and (b) simulations 
and until front passage. This confirms the good stability of the face by the supporting pressure. However, because of shield conicity, there will be ground convergence in the vicinity of the tunnel. Furthermore, because the crown is vertically above the shield, the radial ground convergence is blocked by the interface element, whereas the tangential ground convergence is permitted and, therefore, the ground movements at tunnel shoulders are greater than those at its crown (this is only true for small ground movements). This phenomenon is also shown in field data (Figure 14a), what shows the accuracy of the proposed procedure in predicting ground response to the tunneling process.

As the shield passes the monitoring section, the ground surface settlement increases by about $3 \mathrm{~mm}$ because of the shield conicity. The ground at the tunnel crown settles abruptly by about $7 \mathrm{~mm}$ during the shield passage. The maximum crown settlement at shield tail passage appears to be lower than shield conicity. This can be explained by the migration of part of the grout injected under pressure toward the annular void between the outside surface of the shield and the excavated soil.

At the end of the shield passage, the measurements do not indicate any abrupt surface settlement increase, which shows that the injection of the annular void fulfills its role. The effect of injection pressure is felt on the field in depth as well as at the surface (slight heave at the surface). On Figure 14a, injection pressure lifted the tunnel crown of approximately $5 \mathrm{~mm}$ and it was well reproduced by simulation results. However, in the proposed model, the effect of the injection pressure is not felt at the ground surface and that is why the settlements continue to evolve continuously (Figure14b). In this respect, although the use of Mohr-Coulomb constitutive model is not well adapted to this type of soils, it seems that the choice of the injection pressure made it the right choice, because we can inject enough to reduce surface settlements without observing any significant uplift movement.

On the basis of the aforementioned discussion, the stability of the tunnel face and grouting control are two of the most important parameters for shield control. However, the variation of grouting pressure has a more significant impact on the ground movements. It has to be noted that most difficulties encountered in this 3D simulation are mainly due to difficulty of simply simulated the injection process.

As the shield keeps progressing, the settlements recur and continue to evolve at ground surface as well as at the tunnel crown tending toward an asymptote (Figure 14). This can be explained by the dissipation of the injection pressure and the solidification of the grout. In the proposed model, a gradual reduction in the injection pressure is carried out to avoid any abrupt settlements, especially in the vicinity of the tunnel (Figure 14b). Although the grout characteristics and their evolution related to the advancement of the shield face are not easy to appreciate, the simulations carried out and the choices that have been made seem in good agreement with the field measurements. In particular, the settlements related to the consolidation of the surrounding ground and, to a lesser extent, those related to the grout solidification.

\subsection{Lateral ground movements}

In order to evaluate the accuracy of the proposed model, lateral movements on both sides of the tunnel are compared with field data, as shown in Figure 15.

At first glance, field measurements appear to be well reproduced by the proposed procedure and, at all excavation phases, especially around the tunnel springline. However, the final phases seem to have some discrepancies, especially around silty layers $(6-13 \mathrm{~m})$. This can be explained by the effect of the retaining wall. In fact, the base of the retaining wall, laid on the first silty layer, exerts a strong lateral counterpressure on saturated silty layer and, therefore, prevents the lateral displacements to converge toward the tunnel axis. Another way to explain this is the use of drained analysis for silty and clayey layers. Characterized by a low permeability (close to $10^{-7}$ $\mathrm{m} / \mathrm{s}$ ), an undrained analysis for these layers is preferable and would give numerical results closer to those measured on the inclinometers I17 and I14, respectively. Finally, the fixed center method also has an adverse effect by ignoring the interstitial pressures generated by the shield weight.

\subsubsection{Right side}

Figure 15 shows the inclinometric lateral movements on both sides with respect to the tunnel face advancement. On the right side, the ground around the tunnel springline is pushed outward all along the shield progression to reach about $2 \mathrm{~mm}$ during shield tail passage. In the proposed model, the use of the interface element was decisive in the reproduction of this natural behavior.

The injection pressure pushes the ground to its maximum $(3 \mathrm{~mm})$. After the gradual disappearance of the grouting pressure, the ground begins to converge slightly until it is stabilized far from the shield passage (Figure 16). This convergence is related to the solidification of grout and, most importantly, to the consolidation of surrounding 


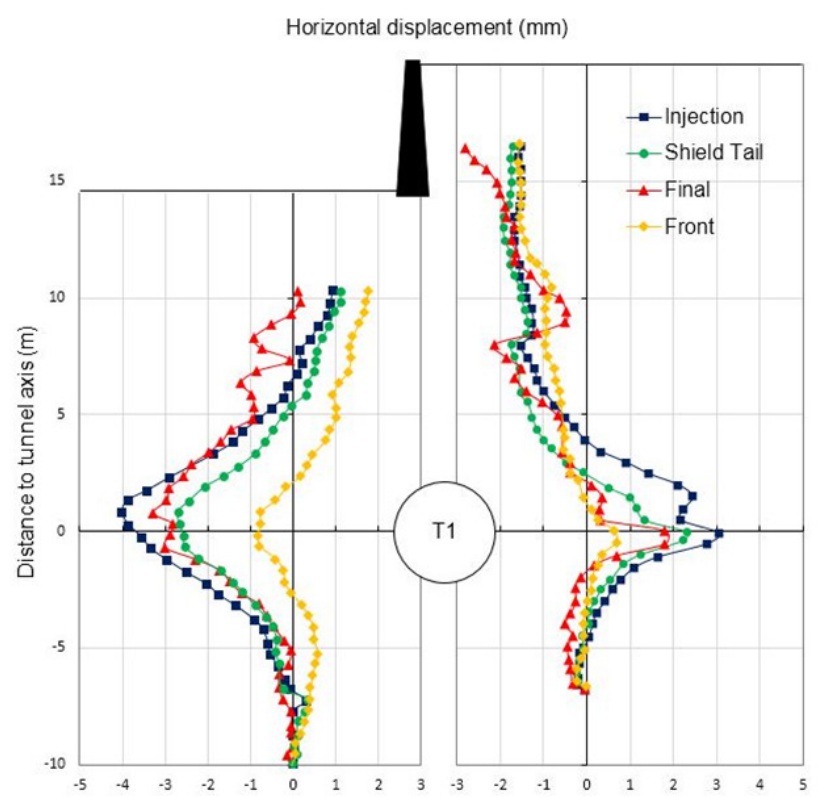

(a)

Figure 15: Lateral movements: (a) field data and (b) simulations.

ground. In the proposed model, this phenomenon is simulated by gradually decreasing the injection pressure and changing the grout characteristics.

If the simulation results around the tunnel axis seem to be in good agreement with field measurements, above the tunnel axis, this is not the case. This is because of the use of some parameters that are revealed to be not adapted. For example, in the proposed model, the drained conditions are considered. But, because the geological profile contains two clayey layers, this choice could be inappropriate and could have adverse effect on ground movements. Another factor influencing the simulation results is the use of Mohr-Coulomb constitutive model. If this model is adapted to describe the behavior of sands and gravels, it is not the case for silts and clays. This model uses the same modulus for loading and unloading (shield progression is a cycle of loading and unloading in the ground mass), which is another source of discrepancy in the numerical response of the ground movements.

\subsubsection{Left side}

On the left side of the tunnel, in general, simulation results are in good agreement with field measurements. The amplitude of displacements around the tunnel axis,

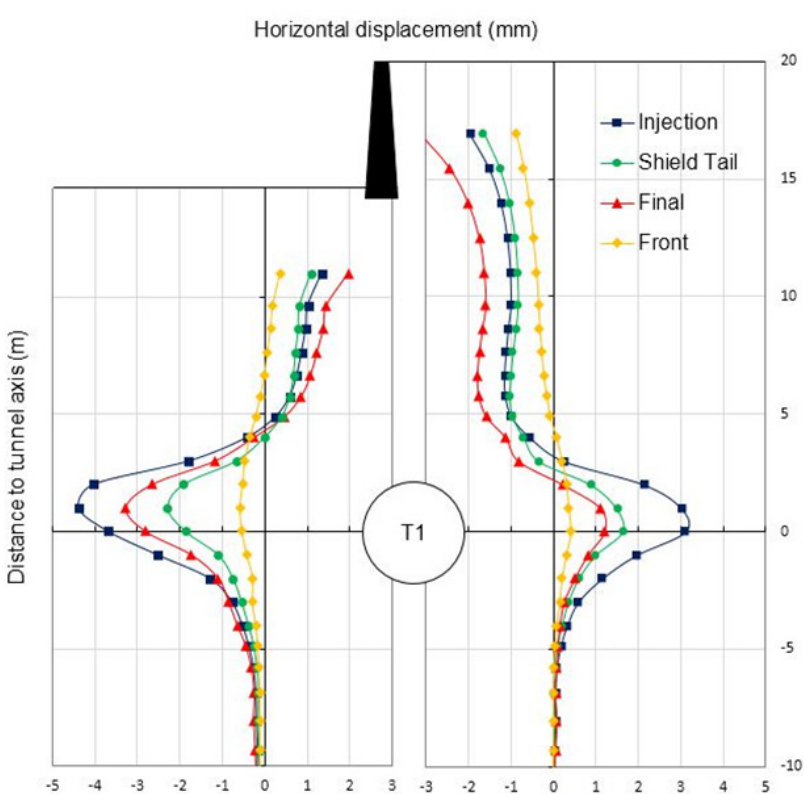

(b)

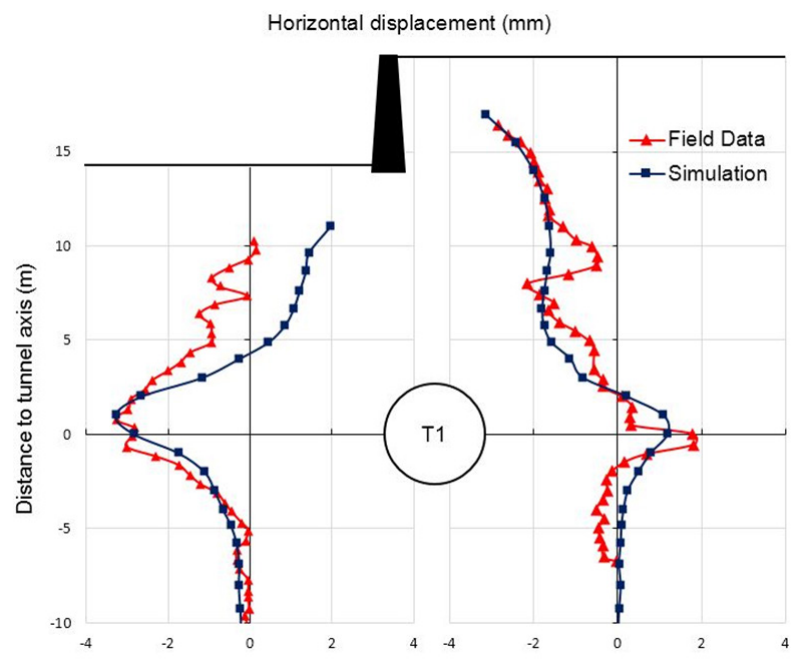

Figure 16: Final lateral movements,

on this side, is greater than that at the right side. This is due to the presence of the retaining wall at the right side, which makes the soil intends to move from the right side to the left one. This singularity is well reproduced by the simulations. Another singularity is the peak of each curve, which is located at about 1 meter above the tunnel axis, and it was also well reproduced by the simulations. 


\section{Conclusions}

A 3D finite difference model was developed to investigate the very good control of ground displacements observed during slurry shield tunneling in Lyon metro project. The proposed model simulates important components of TBM excavation process such as face pressure, shield conicity, tunnel lining, and tail grouting with its solidification. Advanced numerical techniques were used to model shield-soil interaction and grout migration upward the shield. Analysis of tunnel excavation using the proposed procedure provides good agreement with field measurements. From the results of the numerical analysis, the following points can be concluded:

- Moderate face pressure can reduce ground movement significantly and, most importantly, can prevent the occurrence of face instability.

- The effect of the shield conicity is very important and causes appreciable ground movements in slurry shield tunneling. They are certainly more important than settlements induced by inappropriate face pressure.

- Adequate grouting pressure, when it respects the instructions generally used in practical tunneling engineering, can compensate an appreciable fraction of ground settlement.

- Settlement amplitude decreases from the crown to the surface and the settlement trough becomes wider with increasing depth of soil cover.

- Singularities, such as the effect of the retaining wall, were also taken into account. Besides taking the model geometry in its entirety, the retaining wall also has an effect on the results by making the curves dissymmetrical.

- Apart from discrepancies in the ongoing surface settlement during the injection phase, to some extent, good agreement has been acquired from the viewpoint of the prediction of general shape and final value of curves.

In order to capture additional features of shield tunneling process, further improvements of the simulation are needed. Such improvements can be

- Implementation of more sophisticated constitutive models to simulate loading and unloading soil behavior;

- Coupled hydromechanical analysis for the simulation of the actual hydraulic conditions and the distribution of pore pressures because of tunnel advancement and subsequent ground consolidation, which appear to have important effect on ground settlements behind the shield;

- To assess the influence of each component (front pressure, grouting pressure, etc.), only an individual simulation taking into account each of them could investigate their effects on ground movements.

\section{References}

[1]. Benmebarek, S., Kastner, R. \& Ollier, C. (1998). Auscultation et modélisation numérique du processus de creusement à l'aide d'un tunnelier. Geotechnique 48 (6), 801-818. (in french).

[2]. Chakeri H., Ozcelik, Y. \& Unver B. (2013). Effects of important factors on surface settlement prediction for metro tunnel excavated by EPB. Tunnelling and Underground Space Technology, 36, 2013, pp. 14-23.

[3]. Demagh, R., Emeriault, F. \& Hammoud, F. (2013). 3D modelling of tunnel excavation using pressurized tunnel boring machine in overconsolidated soils. Studia Geotechnica et Mechanica, Vol 35, No. 2

[4]. Dias, D., Kastner, R. \& Maghazi, M. (2000). 3D simulation of slurry shield tunnelling. Proceedings of International Symposium on Geotechnical aspects of underground construction in soft ground, Kusakabe, Balkema, Rotterdam, 351-356.

[5]. Dias, D. and Kastner, R. (2013). Movements caused by the excavation of tunnels using face pressurized shields - Analysis of monitoring and numerical modeling results. Engineering Geology, Vol. 152, pp. 17-25.

[6]. Do, NA., Dias, D. Oreste, P. \& Djeran-Maigre, I. (2014). Threedimensional numerical simulation of a mechanized twin tunnels in soft ground. Tunnell Underground Space Technol 2014; 42:40-51.

[7]. Flac ${ }^{30}$, Fast Lagrangian Analysis of Continua in Three Dimensions. Itasca Consulting Group Inc., 2000, Mineapolis.

[8]. Graziani, A., Ribacchi, R. \& Capata, A. (2007). 3D modelling of TBM excavation in squeezing rock masses. In: Brennerr Basistunnel Und Zulaufstrecken, Internationales Symposium BBT. Innsbruck University Press, Innsbruck, pp. 143-151.

[9]. Guglielmetti, V., Grasso, P., Mahtab, A. \& Xu, S. (2008). Mechanized Tunnelling in Urban Areas. Taylor \& Francis Group, London, UK, pp. 212-215.

[10]. Kasper, T. and Meschke, G. (2006). On the influence of face pressure, grouting pressure and TBM design in soft ground tunnelling. Tunnelling and Underground Space Technology, 21: 160-171.

[11]. Kastner, R., Ollier, C. \& Guibert, G. (1996). In situ monitoring of the Lyons Metro D line extension. Geotechnical Aspects of Underground Construction in Soft Ground, Mair \& Tay/or (eds). 1996 Ba/kema, Rotterdam. ISBN 9054108568.

[12]. Katebi, H., Rezaei, A.H., Hajialilue-Bonab, M. \& Tarifard, A. (2015). Assessment the influence of ground stratification, tunnel and surface buildings specifications on shield tunnel lining loads (by FEM). Tunnelling and Underground Space Technology, 49:67-78 
[13]. Li, Z., Grasmick, J. \& Mooney, M. (2015). Influence of slurry TBM parameters on ground deformation. In: ITA WTC 2015 Congress and 41st General Assembly 22-28 May, 2015, Lacroma Valamar Congress Center, Dubrovnik, Croitia.

[14]. Lueprasert, P., Jonpradist, P. \& Suwansawat, S. (2017). Tunneling simulation in soft ground using shell elements and grouting layer. International Journal of GEOMATE, 12(31):51-57

[15]. Maidl, B., Herrenknecht, M., Maidl, U. \& Wehrmeyer, G. (2012). Mechanised shield tunnelling. Berlin: Ernst W. \& Sohn Verlag.

[16]. Mollon, G., Dias, D. \& Soubra, A. H. (2013). Probabilistic analyses of tunnelling-induced ground movements. Acta Geotechnica. http: //dx.doi.org/10.1007/s11440-012- 0182-7.

[17]. Ollier, C. (1997). Etude expérimentale de l'interaction solmachine lors du creusement d'un tunnel peu profond par un tunnelier à pression de boue. Thèse de Doctorat, INSA de Lyon, ISAL 0096.

[18]. Panet, M. (1988). Calcul de soutènement des tunnels à section circulaire par la méthode convergence-confinement. Tunnels et Ouvrages Souterrains 77, 228-232.

[19]. Qiao, Y., Zhao, T. \& Ding, W. (2018). Simulating synchronous grouting in shield tunnels with the consideration of evolution of grouting pressure. In In book: Proceedings of GeoShanghai 2018 International Conference: Tunnelling and Underground Construction, pp. 23-31, 2018.

[20]. Wang, F., Gou, B. \& Qin, Y. (2013). Modeling tunneling-induced ground surface settlement development using a wavelet smooth relevance vector machine. Computers and Geotechnics, 54(0), 125-132.

[21]. Xie, X., Yang, Y. \& Ji, M. (2016). Analysis of surface settlement induced by the construction of a large-diameter shield-driven tunnel in Shanghai, China. Tunnelling and Underground Space Technology, 51:120-132

[22]. Zhang, Z., Zhang, M., Jiang, Y., Bai, Q. \& Zhao, Q. (2017) Analytical prediction for ground movements and liner internal forces induced by shallow tunnels considering non-uniform convergence pattern and ground-liner interaction mechanism. Soils and Foundations. 57: 211-226.

[23]. Zhao, K., Janutolo, M. \& Barla, G. (2012). A completely 3D model for the simulation of mechanized tunnel excavation. Rock Mech. Rock Eng. 45, 475-497. 